\section{EDUCATION AND RESEARCH IN AERONAUTICS}

$\mathrm{T}$ HERE have been many happenings lately that have tended to focus attention upon the subject of the facilities that should be provided in the postwar future to obtain training for the various branches of the profession of aeronautics. The applied side of this science, the design, construction, and maintenance of both fighting service and civil aircraft and engines, the handling of air transport services, and the host of auxiliaries called into being by these, will need a great deal of pioneer work, based on original thinking, for its organization. The advances in the technical outlook made during this, War, together with the problems inseparable from the great increase in the size of the industry, compared with its pre-war dimensions, bring into much prominence the question of training the personnel for the profession.

Many facets of this problem are purely educational and are thus inevitably bound up with the proposals for the reform of the educational system of Great Britain, as foreshadowed by the White Paper on "Educational Reconstruction" presented to Parlia. ment by the President of the Board of Education, and the Norwood Committee's report on "Curriculum and Examinations in Secondary Schools". Following this there are aspects that are general to all those branches of applied science that for convenience can be called engineering. The Institutions of Civil Engineers, Mechanical Engineers, and the Institute of Physics have each issued memoranda upon these. Following this, the particular side of the subject that is aeronautical was the subject of a discussion at meetings of the Royal Aeronautical Society, a report upon which is to be published in due course. The tenth report of the Select Committee on National Expenditure, on aireraft production, also throws valuable light upon the requirements in technical personnel of the aircraft industry as a whole, and comments upon the inadequacy of the supply at present.

The subject of professional education in aeronautics is peculiar in that it is of more recent birth than most of the other professions, and consequently is in a state of immaturity. Most of those intimately connected with it consider that it is suffering from malnutrition, a view supported by the Select Committee's report. The possible remedies are of three kinds. An expansion of the present system, the same expansion with the addition of teaching covering what some consider to be gaps in the existing scheme, or a complete and radical change in the method of approach. Of these the second is the most generally favoured-indeed it appears to be the only one possible. The first is admitted, by experience, to be insufficient, and the last, for fundamental reasons, is impossible in any educational scheme. Within these boundaries there are two outlooks, training in scientific and technical work, and craftsmanship. These two cannot be separated entirely ; indeed, it is from the craftsman that some classes of technical men should be recruited
During the period between the two world wars, steady if not spectacular progress was made in the organizing of training in aeronautics in Great Britain. The many authorities concerned have worked together, and consequently there is functioning to-day a properly co-ordinated scheme that caters for all types of trainees, and is inter-related sufficiently to allow an ambitious candidate to climb the technical ladder to the highest rung if he is mentally capable of doing it. Financially, the position is not yet good. There are a few scholarships devoted specifically to aeronautical training, and many firms in the industry have schemes for helping their apprentices in this respect. The cost of obtaining a part-time training in the technical side of the work, being mostly in the hands of the rate-aided local technical institutions, is not prohibitive to the average apprentice. Under the present war conditions, a small proportion of the State bursaries have been awarded for the study of aeronautical engineering, and the Royal Air Force has a scheme for allowing certain selected technical personnel to study aeronautics, following syllabuses that are of general aeronautical outlook rather than peculiar to Royal Air Force requirements.

The training facilities available in Great Britain at present can be roughly summarized into groups covering the types of trainee envisaged. Repair and maintenance mechanics who are licensed by the Air Ministry, known as 'ground engineers' or 'licensed aircraft engineers', have to pass examinations in certain theoretical aspects of their work. The manufacturing firms, sometimes in conjunction with the local educational authorities, hold classes of this kind. The craftsmen who actually build the firm's products are distinct from these repair men, and do not necessarily hold ground engineer certificates. Their training is of rather a broader outlook and is catered for by the City and Guilds of London Institute (Technological Department), which holds an annual examination ealled "Aeronautical Engineering Practice". Classes for this are held by the local technical institutions. Apprentices needing a more theoretical training can enter for either national certificates sponsored by the Board of Education and the Institution of Mechanical Engineers, external university degrees, or the associate fellowship of the Royal Aeronautical Society, taking such aeronautical subjects as are available in the curriculum at their teaching institution. Some employers allow their apprentices to undertake some form of sandwich system of training, under which they can give sufficient time to theoretical study in their local institution to be considered as full-time students. They then enter for national diplomas or internal degrees, with similar aeronautical subjects. Some entrants prefer to enter upon a full-time course of study direct from school, and leave their practical training until they have obtained their theoretical qualification. They will take similar courses for either national diplomas or university degrees. There is a certain advantage in this latter system in that if a student finds that he has a flair for the more scientific work, and does not wish to take. up the engineering side, he can pass on to study for. the higher branches of scientific research without 
spending his time in a works. The advisability of ignoring the applied side of any science is open to question, but there may be some aspects of aeronautical science, the more mathematical, for example, where an intimate knowledge of the engineering work is not so important. Lastly, there is postgraduate study available for either of the foregoing men who desire to take up the more scientific work and feel that they would profit by a year or more extra study of the particular aspect of the profession that appeals to them. Such students will probably take up either research or the more responsible posts in design or industrial organization.

This is the programme of training as available at the present time, but there is a school of thought that holds the view that there is one serious gap in this. They consider that advanced postgraduate study at a university is academic in character, and while it is correct for the scientific man and research worker, it is not near enough to the applied side for the industrial entrant. They ask for a postgraduate institution of a more practical character, where much of the teaching would be given by visiting lecturers who are actually practising in their profession, and possibly where flying also could be done at the same time. Such flying would, of course, be looked at from the point of view of being supplementary to the technical training being given, and for the development of the technique of flying and its various auxiliary services, rather than the mere mechanical handling of an aircraft. This view was propounded by Sir B. Melvil Jones at a recent meeting of the Royal Aeronautical Society, and it is understood that it is held by a special panel of the Aeronautical Research Committee which is investigating the question of training in aeronautics for the Government.

The problem that has now to be faced in the world of aeronautical training is two-fold. First, it is necessary to consider the present system, that has been functioning to a gradually increasing extent since 1919, and to use the post-war reconstruction period to correct its shortcomings, if any, at the same time allowing for a substantial increase in the size of the industry as compared with 1938, before the commencement of the present War. Such alterations may be necessary both in size and quality. Secondly, it is necessary to organize the practical side of the industrial training, apprenticeship, etc., in such a way that it accommodates itself both to the new conditions in the general educational scheme, and the improved theoretical aeronautical training facilities that will be available consequent upon this enlargement. There will also be an interim problem of dealing with the younger people who have developed an interest in aeronautics by reason of their war-time work, either in the services or industry, and wish to make it their profession. They will have received a partial training in the practical side of the workprobably a specialized but narrow one due to the war-time necessity of becoming expert in one job only-and will need a rather special training to enlarge this and add the theoretical outlook in as short a time as is reasonable.

To come to concrete proposals, the existing scheme is fundamentally correct, and, possibly with the addition of the proposed more practical postgraduate school, adequately covers the ground. At present it fails to bring forward sufficient trained men only because it is not used to its fullest extent. This failure is difficult to explain, but it is none the less very real. To those working behind the scenes in aeronautics, the fact that there were insufficient well-trained persons coming along has been obvious for many years. The sources of supply can be divided roughly into two parts, the apprentice and the fulltime, mostly university, man. The apprentices are taken on in works generally according to numbers agreed upon with the appropriate trades unions, and are presumably sufficient to maintain the supply of new craftsmen. Most of these appear to start on some form of theoretical study under schemes arranged by the employers, but only a woefully small number of them ever reach the stage of taking any of the qualifications that stamp them as being of use for the professional side of aeronautical work. The full-time students' case is different, but the results are equally disappointing. Aeronautics demands fundamental training in the underlying subjects and then adds training in the application of them to its own work. This postulates a longer and more arduous training, which only a few seem to have the ability, enthusiasm, and financial resources to complete. Somehow this source of recruitment to the more technical side of the work must be increased. Fundamentally, the matter would probably settle itself in time if the conditions in the profession were made more attractive; but in the meantime some propaganda would seem to be necessary to rouse sufficient enthusiasm in the minds of the younger men who will be entering their training period in the immediate future. An increase in the number of institutions offering classes in aeronautics would help the general situation, and in this case such educational authorities might be expected to display vision in their programmes, and offer such facilities even though it is not yet established that there exists a Iocal demand for them. Consultations with the local A.T.C. organization might prove a fruitful source of recruitment for the more elementary classes at least.

The failure of so many apprentices to 'stay the course' on the theoretical side indicates that employers might do more to rouse their enthusiasm, and that possibly a certain proportion of the apprenticeships available should be reserved for boys whose school records mark them as being of the more studious type. A proper apprentice supervisor, with the correct outlook and the necessary authority, should be able to watch his charges and possibly allow the more likely ones to give a progressively increasing amount of their time to their technical studies, as they begin to show that they are likely to be of more use in this work than with their hands.

The problem of those returning from the Forces or national service in industry will be as thorny a one as it was after the War of 1914-18, but there is one fact that is outstanding as a result of our experience then. Selection of men to take up the theoretical 
side of aeronautics must be made with great discrimination. A mere interest in the subject, by reason of having done war work of a practical nature in it, is not enough. The special knowledge demanded by the aeronautical profession is not easy to assimilate, and if it has to be done in an intensive course, the difficulties will be even greater. A previous interest in aeronauties added to a good wartime record in it is almost a sine qua non. School qualifications sufficient to be able to understand the work is necessary, but enthusiasm for the profession of aeronautics is equally essential for the hard task that they are undertaking. The man who merely takes up a university course as a way of obtaining a living for the immediate future will always be a problem to the teaching world. That he should be allowed to fill a place in the scheme for higher training in aeronautics, which will be strained to its utmost limit, is unthinkable.

\section{THE ADVANCED THEORY OF STATISTICS}

\section{The Advanced Theory of Statistics}

By Maurice G. Kendall. Vol. 1. Pp. xii +457. (London: Charles Griffin and Co., Ltd., 1943.) 42s. net.

$\mathrm{T}$ HIS very handsomely produced volume is one which it will be a pleasure to any mathematical statistician to possess. Mr. Kendall is indeed to be congratulated on the energy and unswerving perseverance needed to complete his heavy task, and encouraged in the still unflagging energy which will be needed for the second volume. So far as he has carried his work, he has certainly done something to sustain the credit of Great Britain in mathematical scholarship.

In his preface, the author explains that his original intention had been to write in co-operation with four other distinguished statisticians. In the event we must congratulate ourselves on the fortunate fact that the intervention of the War compelled him to carry the work out on his own plan, and without the support and encumbrance of such collaboration.

On the many occasions on which $I$ have been consulted as to the feasibility and desirability of a large-scale work on mathematical statistics, I have pointed to the discouraging circumstance that the advances of recent decades had been so subversive, not only to the methods but also to the points of view from which statistical problems are approached, that any presentation containing material expected by, and acceptable to, the leading minds of an earlier generation would come soon to be recognized as pointless and obsolete. Mr. Kendall deals tactfully with this difficulty, though without altogether solving it. Thus at first sight his contents pay at least formal respect to the old convention of expounding statistical methods under the headings, measures of central tendency, measures of dispersion, and finally, crowning the arch, measures of correlation. The last four of the sixteen chapters in this volume are indeed given up to various coefficients of correlation and association, not, it is true, quite in the old style, for the subjects are treated with a mathematical competence, based on a wide familiarity with the literature, far beyond anything previously attempted, but one is tempted to say also, beyond the intrinsic interest or practical utility of the methods under discussion. Why should anyone now wish to calculate a rank correlation, or a coefficient of contingency ?

The modern reader, on the other hand, would like to see a much fuller development of Chapter 10, on exact sampling distributions, and a far wider and more varied exposition of the uses of the $\chi^{2}$ distribution than is supplied in Chapter 12. In the case of both these chapters; the subjects of which are of the greatest importance to the statistical reader, the approach is barred by an opening section of quite unnecessarily complex algebra. The perfunctory treatment of $x^{2}$ suggests that $\mathrm{Mr}$. Kendall is not immune from the weakness of other heavily burdened authors to scamp those portions of the work in which they are not particularly interested.

The same perfunctory attitude emerges on p. 59 in a short section devoted to the calculation of factorial moments by successive summation. The author says : "The use of the method in practice lies in the fact that for certain calculating machines the progressive summation is easier to carry out than the processes involved in the method of Example 3.1".

From one very highly equipped machinist to another, this may be true enough, though surely an understatement, for a method which replaces a large number of multiplications by an equal number of additions. The saving of labour is evidently most important when no machine is used at all, a condition in which even the most perfectly equipped among us must occasionally work. The method also of abbreviating the process further by summing from both ends to a chosen origin is not given, so that, unless he has independent information, the reader is not in a position to judge how valuable the procedure really is.

The presentation of purely mathematical points is, generally speaking, careful, although, as has already been suggested, cumbrous proofs are sometimes used just where, for the general usefulness of the book, they should have been avoided. Two small points and one of greater importance are perhaps worthy of the author's attention with a view to subsequent editions.

To say, as on p. 53, that "The moment about the mean of order $2 r$, if it exists, is given by" a certain expression is not logically the same as to say that it is defined by the expression, and therefore exists, if the expression has a meaning. Kendall's form of statement suggests, contrary I suppose to his intention, that there is some other condition necessary for the existence of the moment.

In examples 3.7 (p. 59) and 3.8 (p. 66) the symbols $\mu$ and $x$ appropriate to the population are applied to statistics derived from a sample. It is true that the sample is large, giving the heights of more than eight thousand men, and therefore the errors of random sampling will be comparatively small, but it is none the less a pity to confuse the student at this stage by blurring a distinction which will later require his full attention. The other examples, 3.9-3.11, are properly applied to distributions.

Mr. Kendall is much interested in the rather formidable algebra of the symmetric functions used in mathematical statistics. Thus the formulæ for translating moments into cumulants and vice versa are set out in full to the tenth degree on pp. $61-64$, and in other parts of the book a good deal of space is given to proofs establishing similar relationships. In my own experience the approach to all work of this kind is greatly eased for the majority of mathe- 